\title{
Comparison of long-term outcomes of young patients after a coronary event associated with familial hypercholesterolemia
}

\author{
Xu Wang ${ }^{1 \dagger}$, Gaojun Cai ${ }^{2,4 \dagger}$, Yingying Wang ${ }^{5}$, Ran Liu' ${ }^{1}$, Ziwei Xi ${ }^{2}$, Gexuan $\mathrm{Li}^{2}$, Wenhui Wen ${ }^{3}$, Yue Wu ${ }^{3}$, \\ Chenggang Wang ${ }^{1}$, Qingwei $\mathrm{Ji}^{1}$, Xinguo Wang ${ }^{1}$, Qian Zhang ${ }^{1}$, Yujie Zeng ${ }^{1}$, Luya Wang ${ }^{3}$, Wei Liu ${ }^{2 * \dagger}$ and \\ Yujie Zhou ${ }^{2^{*}+}$
}

\begin{abstract}
Objective: Familial hypercholesterolemia (FH) is an important cause of premature coronary artery disease (CAD). Prognosis data are lacking in patients with $\mathrm{FH}$ and coronary artery disease particularly in the era of widespread statin use. We compared long-term prognosis between patients with and without FH after a coronary event.

Methods: In this retrospective study, 865 patients younger than 40 years of age with CAD were enrolled. FH was diagnosed based on the Dutch Lipid Clinic Network algorithm. Baseline characteristics, coronary angiographic findings and prognosis during median follow-up of 5 (3-8) years were compared between patients with or without $\mathrm{FH}$.

Results: Definite or probable FH was detected in 37 patients (4.3\%) and possible FH in 259 patients (29.9\%). FH was associated with significantly higher prevalence of multi-vessel lesions $(p<0.001)$ and higher Gensini score $(p=$ 0.008). In the subset of 706 patients for whom follow-up data were available, 127 (18.0\%) suffered major adverse cardiovascular and cerebrovascular events (MACCE). FH was associated with increased risk of MACCE, independently of age, sex, smoking, body mass index, hypertension or diabetes mellitus ( $\mathrm{HR}=2.30,95 \% \mathrm{Cl}=1.09$ to $4.84, p=0.028)$.

Conclusions: $\mathrm{FH}$ is an independent risk factor for MACCE in young patients after a coronary event during longterm follow-up. It is necessary to optimize lipid treatment of patients with $\mathrm{FH}$ after a coronary event.
\end{abstract}

Keywords: Familial hypercholesterolemia, Coronary event, Outcomes

\section{Introduction}

Familial hypercholesterolemia (FH; MIM 143890) is an autosomal dominant genetic disease characterized by high levels of low-density lipoprotein cholesterol (LDLC), cutaneous xanthomas and premature coronary artery

\footnotetext{
*Correspondence: liuwei@ccmu.edu.cn; azzyj12@163.com

${ }^{+}$Xu Wang and Gaojun Cai are both authors contributed equally to the article as the first authors.

${ }^{+}$Wei Liu and Yujie Zhou are both authors contributed equally to the article as the correspondence authors.

${ }^{2}$ Department of Cardiology, 12th ward, Beijing Anzhen Hospital, Capital Medical University, Beijing Institute of Heart Lung and Blood Vessel Disease, Beijing Key Laboratory of Precision Medicine of Coronary Atherosclerotic Disease, Clinical center for coronary heart disease, Capital Medical University, Beijing 100029, China

Full list of author information is available at the end of the article
}

disease ( $\mathrm{pCAD})$, which has recently become a major health concern around the world [1]. Data suggest that 1 in 200 of Caucasians are heterozygous for $\mathrm{FH}$ and that 1 in 160,000-300,000 are homozygous [2], which are much higher prevalences than those estimated a decade earlier [3]. A study in China has suggested a prevalence of probable or definite $\mathrm{FH}$ of $0.28 \%(1.4 / 500)$ based on the modified Dutch Lipid Clinic Network (DLCN) definition [4]. These studies suggest that nearly 36 million people around the world have potential $\mathrm{FH}$, including 3.8 million in China. FH remains largely underdiagnosed and undertreated. Fewer than $1 \%$ of FH cases are diagnosed in most countries, except in some countries of western Europe [2]. 
Timely detection of $\mathrm{FH}$ is important because the presence of definite or probable $\mathrm{FH}$ increases 13 -fold $(95 \% \mathrm{CI}=10-17)$ risk of CAD compared to the general population [5]. In Europe, $\mathrm{FH}$ occurs in up to $8 \%$ of patients admitted for acute coronary syndromes, a frequency that is 10 times higher than in the general population [6]. For patients with acute coronary syndromes, the diagnosis of $\mathrm{FH}$ during hospitalization helps to ensure the use of high-dose statins and the management of blood lipids after discharge [7].

Whether $\mathrm{FH}$ in CAD alters the clinical manifestations of the disease and the prognosis of patients is unclear. We compared the long-term prognosis of young patients with and without FH after a coronary event.

\section{Methods}

\section{Study population}

Patients with both gender ( $\geq 18$ years and $<40$ years of age) with the following first or recurrent clinical diagnoses or procedures at Beijing Anzhen Hospital from January 2004 to January 2015 were consecutively enrolled in this retrospective study, including those with elective or primary $\mathrm{PCI}$, elective or emergency $\mathrm{CABG}$, acute myocardial infarction (AMI: ICD-10 I21), and acute myocardial ischemia (ICD-10 I20) [8]. The diagnosis of every participate enrolled in this study was confirmed by two experienced cardiologists.

Patients were excluded if blood lipid data were missing or if the patients had infectious or systematic inflammatory disease, significant hematologic disorders, thyroid dysfunction, severe liver and/or renal dysfunction, or malignant tumors.
The study was approved by the Institutional Ethics Committee of Beijing Anzhen Hospital. The Ethics Committee waived the requirement for informed consent because of the retrospective nature of the study.

Patients enrolled in the study were diagnosed with $\mathrm{FH}$ based on the DLCN criteria (Table 1), which are endorsed by ESC/EAS guidelines [9]. Patients were classified as having possible $\mathrm{FH}$ if their DLCN score was 3-5, "definite" FH was $>8$, "probable" FH was 6 8 [10]. In our study, we combined the categories "definite" $\mathrm{FH}$ and "probable" FH into one category (definite/probable FH). Family history of elevated LDL-C was not available for our study sample, so this information was counted as ' 0 ' in the DLCN algorithm. Similarly, genetic tests of $\mathrm{FH}$ were not conducted and were counted as ' 0 '.

\section{Patient assessment}

Data on clinical characteristics were collected based on review of medical records or patient interviews. All patients underwent clinical examination, blood testing and angiography. Peripheral blood samples were drawn from patients within $24 \mathrm{~h}$ after admission, and lipid profiles and other assays were performed using an automated biochemical analyzer. LDL-cholesterol concentrations were multiplied by 1.43 in individuals using cholesterol lowering medication before admission [11]. Hypertension was defined according to the 2010 Hypertension Prevention and Treatment Guidelines [12] as systolic blood pressure $\geq 140 \mathrm{mmHg}$ and/or diastolic blood pressure $\geq 90 \mathrm{mmHg}$ or the taking of antihypertensive medication. Diabetes mellitus was defined

Table 1 Dutch Lipid Clinic Network criteria for diagnosis of heterozygous familial hypercholesterolaemia in adults

\begin{tabular}{|c|c|}
\hline Criteria & Points \\
\hline \multicolumn{2}{|l|}{ Family History } \\
\hline $\begin{array}{l}\text { A First degree relative with known premature }(<55 \text { years men; }<60 \text { years women) coronary disease and vascular disease OR LDL-c }>95 \text { th } \\
\text { percentile }\end{array}$ & 1 \\
\hline B First degree relative with tendon xanthomata and/or arcuscornealis OR childhood ( $<18$ years) with LDL-c $>95$ th percentile & 2 \\
\hline \multicolumn{2}{|l|}{ Clinical history } \\
\hline A Patient with premature CAD (men <55, women <60 years) & 2 \\
\hline B Patient with premature cerebral or PVD (men <55, women <60 years) & 1 \\
\hline \multicolumn{2}{|l|}{ Physical Examination } \\
\hline A Tendon xanthomas & 6 \\
\hline B Premature arcus & 4 \\
\hline \multicolumn{2}{|l|}{ biochemical results (LDL cholesterol) } \\
\hline A LDL - C> $8.5 \mathrm{mmol} / \mathrm{L}$ & 8 \\
\hline B LDL-c $6.5-8.4 \mathrm{mmol} / \mathrm{L}$ & 5 \\
\hline C LDL- c 5.0-6.4 mmol/L & 3 \\
\hline D LDL - c 4.0-4.9 mmol/L & 1 \\
\hline \multicolumn{2}{|l|}{ molecular genetic testing (DNA analysis) } \\
\hline DNA mutations & 8 \\
\hline Definite $\mathrm{FH}:>8$ points, Probable $\mathrm{FH}: 6-8$ points, Possible $\mathrm{FH}: 3-5$ & \\
\hline
\end{tabular}


according to the American Diabetes Association (ADA) Diabetes Diagnostic Criteria [13]. Data were collected on smoking status and body mass index (BMI). After release from hospital, patients were followed up through phone interviews, review of hospital records or outpatient visits.

The primary outcome was main adverse cardiovascular and cerebrovascular events (MACCE), which were defined as cardiac death, acute myocardial infarction, acute decompensated heart failure requiring hospitalization, cerebrovascular events or ischemia-driven revascularization. Ischemia-driven revascularization was defined as repeated PCI or CABG of lesions in the presence of acute myocardial infarction, unstable or stable angina, or documented silent ischemia.

\section{Statistical analysis}

Continuous variables were presented as the mean \pm standard deviation $(\mathrm{SD})$ if the data were normally distributed. Otherwise, the data were presented as median and interquartile range (IQR). Categorical variables were expressed as frequencies and percentages. Differences in clinical characteristics between patients with or without $\mathrm{FH}$ were assessed for significance using one-way ANOVA, $\chi^{2}$ tests or the KruskalWallis rank test. Hazard ratios (HRs) and corresponding 95\% confidence intervals (CIs) were calculated using Cox proportional hazard models. Event-free survival was analyzed using the Kaplan-Meier method, and inter-group differences in survival were assessed for significance using the log-rank test. All statistical calculations were performed in SPSS 22 (IBM, Chicago, IL, USA), with $p<0.05$ defined as indicating significance.

\section{Results}

\section{Baseline characteristics}

Among 865 participants, 37 (4.3\%) had definite/ probable $\mathrm{FH}$ and 259 (29.9\%) had possible $\mathrm{FH}$, respectively. The remaining $569 \quad(65.8 \%)$ received DLCN scores of "unlikely FH" and so were classified as not having $\mathrm{FH}$ (Table 2). Unstable angina pectoris is the main cause of hospitalization in $\mathrm{FH}$ patients (56.8\%), while ST-segment elevation myocardial infarction (STEMI) is a common cause of hospitalization in non-FH patients (57.3\%). Compared with patients without $\mathrm{FH}$, those with definite or probable $\mathrm{FH}$ were younger but showed higher prevalence of multi-vessel disease $(75.7 \%$ vs $34.1 \%)$, chronic total occlusion (CTO) $(45.9 \%$ vs $29.9 \%)$ and greater coronary severity based on Gensini score (50 vs 32). More patients with definite or probable $\mathrm{FH}$ received bypass grafting than those without $\mathrm{FH}$ (32.4\% vs $10.7 \%$ ) (Table 3). When discharge, $75.7 \%$ of patients with definite or probable $\mathrm{FH}$ were on statin therapy, $24.3 \%$ on a combination of statin and ezetimibe, and $5.4 \%$ on high-dose statin.

Table 2 Baseline characteristics of young patients after a coronary event with or without FH

\begin{tabular}{|c|c|c|c|c|c|}
\hline \multirow[t]{2}{*}{ Variable } & \multirow[t]{2}{*}{ Total } & \multicolumn{3}{|l|}{ FH status $^{a}$} & \multirow[b]{2}{*}{$P$} \\
\hline & & $\begin{array}{l}\text { Probable/Definite } \\
\text { ( }>5 \text { points) }\end{array}$ & $\begin{array}{l}\text { Possible } \\
\text { (3-5 points) }\end{array}$ & $\begin{array}{l}\text { None } \\
\text { (<3 points) }\end{array}$ & \\
\hline Number, n (\%) & $865(100)$ & $37(4.3)$ & $259(29.9)$ & $569(65.8)$ & \\
\hline \multicolumn{6}{|l|}{ Demographics } \\
\hline Age, yr & $33(30-34)$ & $31(28-31)$ & $33(31-35)$ & $33(30-34)$ & 0.005 \\
\hline Female, $n(\%)$ & $49(5.7)$ & $2(5.4)$ & $15(5.8)$ & $32(5.6)$ & 0.993 \\
\hline $\mathrm{BMl}, \mathrm{kg} / \mathrm{m}^{2}$ & $27.8(4.09)$ & $26.5(4.58)$ & $28.3(3.82)$ & $27.7(4.15)$ & 0.057 \\
\hline Family history of pCAD, n(\%) & $199(23.0)$ & $21(56.8)$ & $178(68.7)$ & $0(0.0)$ & 0.000 \\
\hline Smoking status, n(\%) & $586(67.7)$ & $28(75.7)$ & $177(68.3)$ & $381(67.0)$ & 0.531 \\
\hline Elevated alcohol consumption, n(\%) & $208(24.0)$ & $9(24.3)$ & $55(21.1)$ & $144(25.3)$ & 0.445 \\
\hline \multicolumn{6}{|l|}{ Past history } \\
\hline Hypertension, n(\%) & $318(36.8)$ & $7(18.9)$ & $110(42.5)$ & $201(35.3)$ & 0.013 \\
\hline Diabetes mellitus, n(\%) & $138(16.0)$ & $2(5.4)$ & $46(18.0)$ & $90(15.7)$ & 0.145 \\
\hline Pre-existing CAD, n(\%) & $162(18.7)$ & $8(21.6)$ & 45 (17.6) & 109 (19.1) & 0.792 \\
\hline \multicolumn{6}{|l|}{ Lipid profiles } \\
\hline $\mathrm{TC}, \mathrm{mmol} / \mathrm{L}$ & $4.58(1.46)$ & $8.10(2.35)$ & $5.02(1.33)$ & $4.15(1.00)$ & 0.000 \\
\hline $\mathrm{LDL}-\mathrm{C}, \mathrm{mmol} / \mathrm{L}$ & $2.92(1.24)$ & $6.37(2.13)$ & $3.30(1.12)$ & $2.53(0.71)$ & 0.000 \\
\hline $\mathrm{HDL}-\mathrm{C}, \mathrm{mmol} / \mathrm{L}$ & $0.90(0.20)$ & $0.91(0.19)$ & $0.91(0.21)$ & $0.89(0.20)$ & 0.472 \\
\hline $\mathrm{TG}, \mathrm{mmol} / \mathrm{L}$ & $1.90(1.29-2.78)$ & $1.56(1.11-2.55)$ & $2.01(1.50-2.98)$ & $1.83(1.27-1.74)$ & 0.017 \\
\hline
\end{tabular}

FH familial hypercholesterolemia, $p C A D$ premature coronary artery disease, $B M I$ body mass index, $T C$ total cholesterol, $L D L-C$ low-density lipoprotein cholesterol, $H D L-C$ low-density lipoprotein cholesterol, TG triglyceride

${ }^{a}$ Based on Dutch Lipid Clinic Network criteria 
Table 3 Clinical features, angiographic characteristics, and treatment of young patients after a coronary event with or without FH

\begin{tabular}{|c|c|c|c|c|c|}
\hline \multirow[t]{2}{*}{ Variable } & \multirow[t]{2}{*}{ Total } & \multicolumn{3}{|l|}{ FH status $^{a}$} & \multirow[b]{2}{*}{$P$} \\
\hline & & $\begin{array}{l}\text { Probable/Definite } \\
\text { ( }>5 \text { points) }\end{array}$ & $\begin{array}{l}\text { Possible } \\
\text { (3-5 points) }\end{array}$ & $\begin{array}{l}\text { None } \\
\text { (<3 points) }\end{array}$ & \\
\hline \multicolumn{6}{|l|}{ Diagnosis } \\
\hline STEMI, n(\%) & $468(54.1)$ & $16(43.2)$ & $126(48.6)$ & $326(57.3)$ & 0.027 \\
\hline NONSTEMI, n(\%) & $75(8.7)$ & $0(0.0)$ & $29(11.2)$ & $46(8.1)$ & 0.054 \\
\hline UAP, n(\%) & $314(36.3)$ & $21(56.8)$ & $101(39.0)$ & $192(33.7)$ & 0.010 \\
\hline SAP, n(\%) & $8(0.9)$ & $0(0.0)$ & $3(1.2)$ & $5(0.9)$ & 0.774 \\
\hline \multicolumn{6}{|l|}{ Coronary angiography } \\
\hline None, n(\%) & $100(11.6)$ & $1(2.7)$ & $33(12.7)$ & $66(11.6)$ & 0.216 \\
\hline Single vessel, n(\%) & $448(51.8)$ & $8(21.6)$ & $131(50.6)$ & $309(54.3)$ & 0.001 \\
\hline Double vessel, n(\%) & $195(22.5)$ & $13(35.1)$ & $57(22.3)$ & $125(21.9)$ & 0.173 \\
\hline Triple vessel, n(\%) & $110(12.7)$ & $13(35.1)$ & $34(13.1)$ & $63(11.1)$ & 0.000 \\
\hline Left main, n(\%) & $61(7.1)$ & $3(8.1)$ & $13(5.0)$ & $45(7.9)$ & 0.312 \\
\hline CTO, n(\%) & $270(31.2)$ & $17(45.9)$ & $83(32.2)$ & $170(29.9)$ & 0.115 \\
\hline Multivessel lesion, n (\%) & 317 (36.6) & $28(75.7)$ & $95(36.7)$ & $194(34.1)$ & 0.000 \\
\hline Gensini & $32(10-64)$ & $50(14-82)$ & $32(10-64)$ & $32(9-56)$ & 0.008 \\
\hline \multicolumn{6}{|l|}{ Operation } \\
\hline $\mathrm{PCl}, \mathrm{n}(\%)$ & $539(62.3)$ & $20(54.1)$ & $176(68.0)$ & $343(60.3)$ & 0.061 \\
\hline CABG, n(\%) & $90(10.4)$ & $12(32.4)$ & $17(6.6)$ & $61(10.7)$ & 0.000 \\
\hline PTCA, n(\%) & $20(2.3)$ & $0(0.0)$ & $6(2.3)$ & $14(2.5)$ & 0.628 \\
\hline \multicolumn{6}{|l|}{ Medication at discharge } \\
\hline Aspirin, $n(\%)$ & $819(94.7)$ & $36(97.3)$ & 251 (96.9) & $532(93.5)$ & 0.098 \\
\hline$\beta$-blocker, n(\%) & $701(81.0)$ & $26(70.3)$ & $216(83.4)$ & $459(80.7)$ & 0.151 \\
\hline ACEI/ARB, n(\%) & $472(54.6)$ & $13(35.1)$ & $146(56.4)$ & $313(55.0)$ & 0.049 \\
\hline Statins, n(\%) & $719(83.1)$ & $28(75.7)$ & $226(87.3)$ & $465(81.7)$ & 0.067 \\
\hline High-dose statins, n(\%) & $67(7.7)$ & $2(5.4)$ & $21(8.1)$ & $44(7.7)$ & 0.847 \\
\hline Ezetimibe, n(\%) & $40(4.6)$ & $9(24.3)$ & $15(5.8)$ & $16(2.8)$ & 0.000 \\
\hline
\end{tabular}

FH familial hypercholesterolemia, $p C A D$ premature coronary artery disease, STEMI ST-segment elevation myocardial infarction, NONSTEMI Non-ST-segment elevation myocardial infarction, UAP Unstable angina pectoris, SAP Stable angina pectoris, CTO chronic total occlusion, CABG coronary artery bypass grafting, PCI percutaneous coronary intervention, PTCA percutaneous transluminal coronary angioplast, $A C E / / A R B$ angiotensin converting enzyme inhibitors/angiotensin receptor blocker

aBased on Dutch Lipid Clinic Network criteria

\section{The association between FH and risk of MACCE}

Follow-up data were available for $708(81.8 \%)$ patients, while the remaining patients were lost to follow-up, such as because they moved or changed their telephone number. During follow-up, which lasted for a median of 5 (3-8) years, one patient without $\mathrm{FH}$ died of leukemia and one without FH died of a brain tumor. These two patients were excluded from the follow-up analysis. Among the remaining 706 follow-up patients, 127 (18.0\% of all patients followedup) experienced a cardiovascular event, which was myocardial infarction in 36 cases (5.1\% of all patients followed-up) and cardiac deaths in 15 cases (2.1\% of all patients followedup), respectively. In an unadjusted model, patients with definite or probable $\mathrm{FH}$ were at 2.34-fold higher risk of MACCE than those without $\mathrm{FH}(\mathrm{HR}=2.34,95 \% \mathrm{CI}=1.17-4.68, p=$ 0.016). In a multivariable model adjusted for age and sex, patients with definite or probable $\mathrm{FH}$ were at 2.39-fold higher risk of MACCE than patients without $\mathrm{FH}(\mathrm{HR}=2.39$, $95 \% \mathrm{CI}=1.19-4.78, p=0.014)$. These HR estimates did not decrease when the multivariable model also adjusted for BMI, smoking, hypertension, and diabetes mellitus $(\mathrm{HR}=$ 2.30, $95 \% \mathrm{CI}=1.09-4.84, p=0.028$ ) (Table 4 ).

\section{Discussion}

This study suggests that the prevalence of definite or probable FH among young patients after a coronary event was $4.3 \%$, while that of possible $\mathrm{FH}$ was $29.9 \%$, based on the DLCN algorithm. In our cohort, FH was associated with more serious coronary lesions and greater prevalence of multi-vessel disease, despite being associated with younger age. FH was independently associated with increased risk of MACCE during long- 
Table 4 Multivariable analysis of the association between FH and risk of MACCE

\begin{tabular}{lllllll}
\hline FH status $^{\text {a }}$ & $\begin{array}{l}\text { Participants } \\
(\mathrm{n})\end{array}$ & $\begin{array}{l}\text { MACCE } \\
(\mathrm{n})\end{array}$ & $\begin{array}{l}\text { Incidence rate } \\
(\text { per } 100 \text { person-y) }\end{array}$ & $\begin{array}{l}\text { Unadjusted } \\
\text { HR (95\% Cl) }\end{array}$ & $\begin{array}{l}\text { Model } 1 \\
\text { HR (95\% Cl) }\end{array}$ & $\begin{array}{l}\text { Model } 2 \\
\text { HR (95\% Cl) }\end{array}$ \\
\hline No FH (Score $<3)$ & 453 & 73 & 2.5 & 1.00 (Referent) & 1.00 (Referent) & 1.00 (Referent) \\
Possible FH (Score 3-5) & 223 & 45 & 3.3 & $1.30(0.89-1.88)$ & $1.30(0.90-1.89)$ & $1.16(0.77-1.75)$ \\
Probable/Definite FH & 30 & 9 & 5.8 & $2.34(1.17-4.68)$ & $2.39(1.19-4.78)$ & $2.30(1.09-4.84)$
\end{tabular}

(Score > 5)

FH familial hypercholesterolemia, MACCE major adverse cardiovascular and cerebrovascular events, $H R$ hazard ratio, $C l$ confidence interval. Model 1, adjusted for age and sex. Model 2, adjusted for age, sex and cardiovascular risk factors, including current smoking, hypertension, diabetes mellitus, and BMI

aased on Dutch Lipid Clinic Network criteria

term follow-up. Our study suggests that timely diagnosis of FH may help stratify the risk of future MACCE in young patients after a coronary event, as well as identify patients whose close relatives should be screened.

Due to lack of national data, we cannot compare our measured prevalence of $4.3 \%$ for definite or probable $\mathrm{FH}$ in our cohort with statistics for the population of CAD patients or the general population in China. A singlecenter study in China reported a prevalence of $3.9 \%$ for definite or probable $\mathrm{FH}$ in patients with acute myocardial infarction and $7.1 \%$ in patients with premature myocardial infarction [14]. A European multi-country study involving 1451 patients with premature acute coronary syndrome and younger than 55 years (men) or 60 years (women) reported prevalence of $4.8 \%$ for definite or probable $\mathrm{FH}$ and $47.1 \%$ for possible $\mathrm{FH}$ [6].

As a hereditary disease, the clinical diagnostic criteria of FH can identify FH rapidly and costly. We found that patients with definite or probable $\mathrm{FH}$, despite their younger age, exhibited more severe coronary atherosclerosis and higher prevalence $(75.7 \%)$ of multi-vessel lesions than patients without $\mathrm{FH}$ (34.1\%). Patients with $\mathrm{FH}$ tend to receive lipid-lowering treatment relatively late, when severe atherosclerosis has developed, and the efficacy of lipid-lowering therapy may be reduced. In addition, we found that few of patients with $\mathrm{FH}$ in this study were discharged on high-dose statin therapy. Instead, our clinicians preferred to use moderate doses of statins on their own or combined with ezetimibe or bile acid sequestrants in order to enhance lipid-lowering therapy while minimizing the statin-associated risk of elevated liver enzymes and creatine kinase. Statin monotherapy fails to achieve optimal LDL-C levels in most patients with FH [15]. More effective lipid-lowering strategies include high-dose statin in combination with evolocumab $[16,17]$ or ezetimibe. Bile acid sequestrants are rarely used because of their adverse gastrointestinal side effects and poor patient compliance. Colesevelam has stronger ability to bind bile acid. Monotherapy with colesevelam reduced LDL cholesterol by $13-19 \%$ and additional $18 \%$ in combination with statins [18]. While treatment for CAD patients with $\mathrm{FH}$ remains to be optimized, statins can substantially improve prognosis: modest doses of statins can reduce risk of CAD by about $80 \%$ in patients with $\mathrm{FH} \mathrm{[19],} \mathrm{and} \mathrm{a} \mathrm{prospective}$ registry study involving 3382 patients with $\mathrm{FH}$ showed that statins can reduce coronary mortality by $30 \%$ [20].

With regard to clinical outcomes, we found that definite or probable FH had a $>2$-fold increase MACCE during a longterm follow-up comparing with the patients without $\mathrm{FH}$. This association between FH clinical diagnosis and MACCE was independent of conventional risk factors. Since the lipidlowering therapy in patients with $\mathrm{FH}$ is generally quite late, the coronary artery lesions in patients with $\mathrm{FH}$ are more serious. This may be one of the reasons for the adverse outcomes in these patients. In addition, even after a coronary event, the rate of high-dose statin therapy in FH patients was fairly inadequate in this cohort. These patients were still exposed to high levels of LDL-C. Furthermore, though some patients with FH were treated with high-dose statin combined with ezetimibe, part of them still could not attain the desirable targets of LDL-C levels. For these patients, novel lipid-lowering drugs such as proprotein convertase subtilisin kexin 9 inhibitors are expected to further decrease the LDL-C levels and improve cardiovascular outcomes [21, 22].

In conclusion, early diagnosis and treatment are crucial for improving the outcomes of $\mathrm{FH}$ patients. Screening for $\mathrm{FH}$ may allow timelier and therefore more effective lipid management in CAD patients with FH. It may also identify patients whose close family members should be screened for FH in order to ensure timely intervention to prevent cardiovascular events.

\section{Limitations}

The results of this study should be interpreted with caution in light of several limitations. One is the retrospective design, although all patients were followed up prospectively. Secondly, we did not perform genetic molecular analysis to identify heterozygous $\mathrm{FH}$ patients. In addition, not all patients received similar treatment. Finally, family history of elevated LDL-C was not available for the presents study, which might underestimate the prevalence of $\mathrm{FH}$ in this population.

\section{Conclusions}

It is necessary to optimize lipid treatment of patients with FH after a coronary event. This study provides evidence that $\mathrm{FH}$ is an independent risk factor for long-term MACCE in young patients after a coronary event. 


\section{Abbreviations}

ACEI/ARB: angiotensin converting enzyme inhibitors/angiotensin receptor blocker; BMI: body mass index; CABG: coronary artery bypass grafting; CAD: Coronary artery disease; CTO: chronic total occlusion; FH: Familial hypercholesterolemia; HDL-C: High density lipoprotein cholesterol; LDLC: low-density lipoprotein cholesterol; MACCE: major adverse cardiovascular and cerebrovascular events; NONSTEMI: Non-ST-segment elevation myocardial infarction; pCAD: Premature coronary artery disease; PCl: percutaneous coronary intervention; PTCA: percutaneous transluminal coronary angioplast; SAP: Stable angina pectoris; STEMI: ST-segment elevation myocardial infarction; TC: Total cholesterol; TG: Triglyceride; UAP: Unstable angina pectoris

\section{Acknowledgements}

We thank all our colleagues at the Emergency \& Critical Care Center and the department of Cardiology, Beijing Anzhen Hospital, Capital Medical University.

\section{Authors' contributions}

Study conception and design: WL, YJZ. Literature search: XW, GJC. Data collection and analysis: XW, GJC, YYW, RL, ZWX, GXL, WHW, YW, CGW, QWJ, XGW, QZ, YJZ, LYW. Data interpretation: XW, GJC, Writing: XW, GJC. All authors read and approved the final manuscript.

\section{Funding}

This work was supported by the grant from Chinese Cardiovascular Association-Access found (2017-CCA-AF-002), Chinese Cardiovascular Association-V.G found (2017-CCA-VG-003), Beijing Municipal Science and Technology Commission (Z161100000116073), National Key Research and Development Program of China (2017YFC0908800), Beijing Municipal Administration of Hospitals' Ascent Plan (DFL20150601) and Mission plan (SML20180601), Beijing Municipal Health Commission "Project of Science and Technology Innovation

Center"(PXM2019_026272_000006)(PXM2019_026272_000005).

\section{Availability of data and materials}

The datasets used and/or analyzed during the current study will be available from the corresponding author on reasonable requests after study completion.

\section{Ethics approval and consent to participate}

This study was complied with the Declaration of Helsinki and approved by the Institutional Ethics Committee of Beijing Anzhen Hospital. Written informed consent was not obtained from the participants, because of the data retrospectively obtained from electronic medical records.

\section{Consent for publication}

Not applicable.

\section{Competing interests}

The authors declare that they have no competing interests.

\footnotetext{
Author details

${ }^{1}$ Emergency \& Critical Care Center, Beijing Anzhen Hospital, Capital Medical University, Beijing 100029, China. ${ }^{2}$ Department of Cardiology, 12th ward, Beijing Anzhen Hospital, Capital Medical University, Beijing Institute of Heart Lung and Blood Vessel Disease, Beijing Key Laboratory of Precision Medicine of Coronary Atherosclerotic Disease, Clinical center for coronary heart disease, Capital Medical University, Beijing 100029, China. ${ }^{3}$ Beijing Institute of Heart Lung and Blood Vessel Disease, the Key Laboratory of Remodeling-related Cardiovascular Disease, Ministry of Education, Beijing Anzhen Hospital, Capital Medical University, Beijing 100029. China. ${ }^{4}$ Department of Cardiology, Wujin Hospital affiliated with Jiangsu University, Changzhou 213017, Jiangsu, China. ${ }^{5}$ Department of Emergency, Tongliao Hospital, Tongliao 028000, Inner Mongolia, China.
}

Received: 6 February 2019 Accepted: 17 May 2019

Published online: 01 June 2019

\section{References}

1. Watts GF, Gidding S, Wierzbicki AS, Toth PP, Alonso R, Brown WV, Bruckert E, Defesche J, Lin KK, Livingston M, Mata P, Parhofer KG, Raal FJ, Santos RD, Sijbrands EJ, Simpson WG, Sullivan DR, Susekov AV, Tomlinson B, Wiegman A, Yamashita S, Kastelein JJ. Integrated guidance on the care of familial hypercholesterolaemia from the international FH Foundation. Int I Cardiol. 2014:171(3):309-25. 24418289.

2. Nordestgaard BG,Chapman MJ, Humphries SE, Ginsberg HN, Masana L, Descamps OS, Wiklund O, Hegele RA, Raal FJ, Defesche JC, Wiegman A, Santos RD, Watts GF, Parhofer KG, Hovingh GK, Kovanen PT, Boileau C, Averna M, Borén J, Bruckert E, Catapano AL, Kuivenhoven JA, Pajukanta P, Ray K, Stalenhoef AF, Stroes E, Taskinen MR, Tybjærg-Hansen A; European Atherosclerosis Society Consensus Panel. Familial hypercholesterolaemia is underdiagnosed and undertreated in the general population: guidance for clinicians to prevent coronary heart disease: consensus statement of the European atherosclerosis society. Eur Heart J 2013, 34: 3478-3490a. [PMID: 23956253].

3. Austin MA, Hutter CM, Zimmern RL, Humphries SE. Genetic causes of monogenic heterozygous familial hypercholesterolemia: a HuGE prevalence review. Am J Epidemiol 2004, 160(5): 407-420. [PMID: 15321837].

4. Shi Z, Yuan B, Zhao D, Taylor AW, Lin J, Watts GF. Familial hypercholesterolemia in China: prevalence and evidence of underdetection and undertreatment in a community population. Int J Cardiol. 2014:174: 834-6. 24801084.

5. ScientificSteeringCommitteeonbehalfoftheSimonBroomeRegister Group. Mortality in treated heterozygous familial hypercholesterolaemia: implications for clinical management. Atherosclerosis. 1999;142(1):105-12. 9920511.

6. Nanchen D, Gencer B, Auer R, Räber L, Stefanini GG, Klingenberg R, Schmied $C M$, Cornuz J, Muller $O$, Vogt $P$, Jüni $P$, Matter CM, Windecker S, Lüscher TF, Mach F, Rodondi N. Prevalence and management of familial hypercholesterolaemia in patients with acute coronary syndromes. Eur Heart J. 2015;36(36):2438-45. 26142466.

7. Rerup SA, Bang LE, Mogensen UM, Engstrøm T, Jørgensen E, Pedersen F, Torp-Pedersen C, Gislason G, James S, Hagström E, Køber L, Fosbøl EL. The prevalence and prognostic importance of possible familial hypercholesterolemia in patients with myocardial infarction. Am Heart J. 2016;181:35-42. 27823691.

8. De Backer G, Besseling J, Chapman J, Hovingh GK, Kastelein JJ, Kotseva K, Ray K, Reiner Ž, Wood D, De Bacquer D, EUROASPIRE Investigators. Prevalence and management of familial hypercholesterolaemia in coronary patients: an analysis of EUROASPIRE IV, a study of the European Society of Cardiology. Atherosclerosis. 2015;241(1):169-75. 25997074.

9. European Association for Cardiovascular Prevention \& Rehabilitation, Reiner Z Catapano AL, De Backer G, Graham I, Taskinen MR, Wiklund O, Agewall S, Alegria E, Chapman M, Durrington P, Erdine S, Halcox J, Hobbs R, Kjekshus J, Filardi PP, Riccardi G, Storey RF, Wood D. ESC/EAS Guidelines for the management of dyslipidaemias: the Task Force for the management of dyslipidaemias of the European Society of Cardiology (ESC) and the European Atherosclerosis Society (EAS). Eur Heart J. 2011, 32(14): 1769-1818. [PMID: 21712404].

10. Civeira F. International panel on Management of Familial Hypercholesterolemia. Guidelines for the diagnosis and management of heterozygous familial hypercholesterolemia. Atherosclerosis. 2004, 173 (1): 55-68. [PMID: 15177124]

11. Benn M, Watts GF, Tybjaerg-Hansen A, Nordestgaard BG. Familial hypercholesterolemia in the Danish general population: prevalence, coronary artery disease, and cholesterol-lowering medication. J Clin Endocrinol Metab. 2012;97:3956-64. 22893714.

12. Liu LS. Writing group of 2010 Chinese guidelines for the Management of Hypertension. 2010 Chinese guidelines for the management of hypertension. Zhonghua Xin Xue Guan Bing Za Zhi 2011, 39(7): 579-615. [PMID: 22088239].

13. American Diabetes Association. Introduction standards of medical care in diabetes-2018. Diabetes Care. 2018 Jan;41(Suppl 1):S13-S27. [PMID: 29222373].

14. Li S, Zhang Y, Zhu CG, Guo YL, Wu NQ, Gao Y, Qing P, Li XL, Sun J, Liu G, Dong Q, Xu RX, Cui CJ, Li JJ. Identification of familial hypercholesterolemia in patients with myocardial infarction: a Chinese cohort study. J Clin Lipidol. 2016;10(6):1344-52. 27919351.

15. Polychronopoulos $G$, Tziomalos K. Novel treatment options for the management of heterozygous familial hypercholesterolemia. Expert Rev Clin Pharmacol. 2017;10(12):1375-81. 28884604. 
16. Robinson JG, Nedergaard BS, Rogers WJ, Fialkow J, Neutel JM, Ramstad D, Somaratne R, Legg JC, Nelson P, Scott R, Wasserman SM, Weiss R, LAPLACE2 Investigators. Effect of evolocumab or ezetimibe added to moderate- or high-intensity statin therapy on LDL-C lowering in patients with hypercholesterolemia: the LAPLACE-2 randomized clinical trial. JAMA. 2014; 311(18):1870-82. 24825642. https://doi.org/10.1001/jama.2014.4030.

17. Wilson PWF, Polonsky TS, Miedema MD, Khera A, Kosinski AS, Kuvin JT. Systematic Review for the 2018. AHA/ACC/AACVPR/AAPA/ABC/ACPM/ADA AGS/APhA/ASPC/NLA/PCNA Guideline on the Management of Blood Cholesterol: A Report of the American College of Cardiology/American Heart Association Task Force on Clinical Practice Guidelines. J Am Coll Cardiol. 2018. Doi https://doi.org/10.1016/j.jacc.2018.11.004. [Epub ahead of print] [PMID: 30423394].

18. Alonso R, Perez de Isla L, Muñiz-Grijalvo O, Diaz-Diaz JL, Mata P. Familial Hypercholesterolaemia diagnosis and management. Eur Cardiol 2018, 13(1): 14-20. [PMID: 30310464].

19. Versmissen J, Oosterveer DM, Yazdanpanah M, Defesche JC, Basart DC, Liem AH, Heeringa J, Witteman JC, Lansberg PJ, Kastelein JJ, Sijbrands EJ. Efficacy of statins in familial hypercholesterolaemia: a long term cohort study. BMJ. 2008;337:a2423. 19001495.

20. Neil A, Cooper J, Betteridge J, Capps N, McDowell I, Durrington P, Seed M, Humphries SE. Reductions in all-cause, cancer, and coronary mortality in statin-treated patients with heterozygous familial hypercholesterolaemia: a prospective registry study. Eur Heart J. 2008:29(23):2625-33. 18840879.

21. Santos RD, Watts GF. Familial hypercholesterolaemia: PCSK9 inhibitors are coming. Lancet. 2015;385:307-10. 25282517. https://doi.org/10.1016/S01406736(14)61702-5.

22. Raal FJ, Stein EA, Dufour R, Turner T, Civeira F, Burgess L, Langslet G, Scott R, Olsson AG, Sullivan D, Hovingh GK, Cariou B, Gouni-Berthold I, Somaratne R, Bridges I, Scott R, Wasserman SM, Gaudet D, RUTHERFORD-2 Investigators. PCSK9 inhibition with evolocumab (AMG 145) in heterozygous familial hypercholesterolaemia (RUTHERFORD-2): a randomised, double-blind, placebo-controlled trial. Lancet. 2015;385:331-40. 25282519. https://doi.org/ 10.1016/50140-6736(14)61399-4.

\section{Publisher's Note}

Springer Nature remains neutral with regard to jurisdictional claims in published maps and institutional affiliations.

Ready to submit your research? Choose BMC and benefit from:

- fast, convenient online submission

- thorough peer review by experienced researchers in your field

- rapid publication on acceptance

- support for research data, including large and complex data types

- gold Open Access which fosters wider collaboration and increased citations

- maximum visibility for your research: over $100 \mathrm{M}$ website views per year

At $\mathrm{BMC}$, research is always in progress.

Learn more biomedcentral.com/submissions 